\title{
A PROTEÇÃO JURÍDICA INTERNACIONAL DO BIOMA PANTANAL NA ERA DO ANTROPOCENO À LUZ DAS CONSTITUIÇÓES DO BRASIL, BOLÍVIA E PARAGUAI
}

\author{
INTERNATIONAL LEGAL PROTECTION OF THE PANTANAL BIOME IN \\ THE ANTHROPOCENE AGE IN THE LIGHT OF THE CONSTITUTIONS \\ OF BRAZIL, BOLIVIA AND PARAGUAY
}

\author{
Lívia Gaigher Bósio Campello ${ }^{\mathrm{I}}$ \\ Joseliza Alessandra Vanzela Turine ${ }^{\text {II }}$ id \\ Rodrigo de Oliveira Ferreira ${ }^{\mathrm{III}}$
}

\footnotetext{
${ }^{\mathrm{I}}$ Universidade Federal de Mato Grosso do Sul, Campo Grande, MS, Brasil. Doutor em Direito. E-mail: liviagaigher@gmail.com

${ }^{\text {II }}$ Universidade Federal de Mato Grosso do Sul, Campo Grande, MS,

Brasil. Doutora em Biotecnologia e Biodiversidade. E-mail: joselizav@gmail. com

III Universidade Federal de Mato Grosso do Sul, Campo Grande, MS, Brasil. Mestrando em Direito. E-mail: gdfrodrigoferreira@gmail.com
}

\begin{abstract}
Resumo: A crise ecológica evidenciada na era do Antropoceno carrega diversos dilemas e desafios. O Pantanal é a maior planície inundável continental do mundo e sofre as consequências dessa era geológica. Esse bioma apresenta grande importância para a manutenção do equilíbrio ambiental, ecológico, biológico e hidrológico, evidenciando a necessidade de protegê-lo e conservá-lo para as presentes e futuras geraçóes. Por outro lado, o Pantanal, apresenta latente fragilidade, pois intervençóes humanas realizadas de forma inadequada e irracional ocasionam sua degradação. Nesse sentido, a cooperação internacional entre Brasil, Paraguai e Bolívia, alinhada na Constituição de cada país, é necessária para a eficácia da proteção do Pantanal transfronteiriço. O artigo tem como objetivo analisar a crise ecológica global no contexto do Antropoceno, estudar o atual cenário ecológico do Pantanal e, por fim, verificar os mecanismos de proteção internacional do Pantanal, com ênfase nas Constituiçóes de Brasil, Bolívia e Paraguai. Para tanto, a pesquisa é exploratória e descritiva, bibliográfica e documental, com consultas à doutrinas, artigos, documentos internacionais e legislaçóes. O método é o dedutivo, partindo de um conceito geral até sua particularização.
\end{abstract}

Palavras-chave: Crise ecológica. Antropoceno. Pantanal. Proteção jurídica internacional.

Abstract: The ecological crisis evidenced in the Anthropocene era carries several dilemmas and challenges. Pantanal is the largest continental floodplain in the world and suffers the consequences of this geological era. This biome is of great importance for the maintenance of environ-mental, ecological, biological and hydrological balance, highlighting the need to protect and conserve it for present and future generations. On the other hand, the Pantanal, presents 
latent fragility, because human interventions carried out inappropriately and irrationally cause their degradation. In this sense, international cooperation between Brazil, Paraguay and Bolivia, aligned with the constitution of each country, is necessary for the effective protection of the cross-border Pantanal. The article aims to analyze the global ecological crisis in the context of the Anthropocene, to study the current ecological scenario of the Pantanal and, finally, to verify the mechanisms of international protection of the Pantanal, with emphasis on the Constitutions of Brazil, Bolivia and Paraguay. To this end, the research is exploratory and descriptive, bibliographic and documentary, with consultations on doctrines, articles, international documents and legislation. The method is deductive, starting from a general concept until its particularization.

Keywords: Ecological crisis. Anthropocene. Pantanal. International legal protection.

\section{Introdução}

crise ecológica global é um dos maiores desafios a ser enfrentado pela humanidade
no século XXI, suas origens estão intimamente relacionadas com o modo como o ser humano se posiciona frente à natureza e visualiza suas interaçóes com o meio que o rodeia. A ideia de natureza objeto e propriedade, ao colocar o meio ambiente como instrumento disponível para a livre utilização humana, colaborou para o desencadeamento da atual crise ecológica.

As intervençôes humanas alcançaram tal magnitude ao ponto de interferir na geologia e representar um rompimento com uma época geológica denominada Holoceno, a qual era marcada pela estabilidade das condiçôes ambientais que colaborou para o desenvolvimento das sociedades contemporâneas. Emerge, portanto, uma nova época geológica, denominada Antropoceno, representando, claramente, os resultados das açóes antrópicas no planeta e, por conseguinte, sendo também a época da crise ecológica global.

As manifestaçôes de tal crise podem ser verificadas em inúmeros contextos mundiais, como as mudanças climáticas, ocasionadas pelo aquecimento global, a desertificação, desmatamento, perda da biodiversidade. Como resultado dessa problemática, grande alerta repousa no que concerne à proteção das zonas úmidas, como, por exemplo, o Pantanal, as quais estấo, com maior frequência, sofrendo com as pressões antrópicas em seus ecossistemas. Com efeito, o presente trabalho questiona como se dá a proteção jurídica internacional do bioma Pantanal frente às ameaças decorrentes da crise ecológica na época do Antropoceno? Há cooperação entre os países que abrigam o Pantanal?

Com o propósito de responder o referido problema, o trabalho tem como objetivo: analisar a crise ecológica global no contexto do Antropoceno; estudar o atual cenário ecológico do Pantanal com destaque às suas problemáticas socioambientais, verificar os mecanismos de proteção internacional do Pantanal enquanto zona úmida e, por fim, analisar se as Constituiçóes de Brasil, Bolívia e Paraguai estabelecem bases para a cooperação entre esses países para a 
proteção do Pantanal. Para tanto, será utilizada a pesquisa exploratória e descritiva, bibliográfica e documental, consultando doutrinas, artigos, documentos internacionais e legislaçóes. $\mathrm{O}$ método será o dedutivo, partindo de conceitos gerais até sua particularização.

\section{A crise ecológica na era do Antropoceno sob o paradigma do desenvolvimento sustentável}

A crise ecológica consiste em um dos grandes problemas da atualidade. A ideia utilitarista, da natureza como objeto, que se encontra disponível para a livre utilização pelo homem, contribuiu para a adoção de um modelo de desenvolvimento econômico que dá preferência a um crescimento econômico a curto prazo, com a utilização desenfreada dos recursos naturais, não compatível com o desenvolvimento sustentável.

O capitalismo colaborou para a instrumentalização da natureza, transformando a natureza em um produto, um objeto dotado de valor econômico a ser explorado livremente pelo ser humano. Assim, "o homem [foi] alçado à detentor da natureza, uma vez que tem o poder de transformá-la e dominá-la”"

Essa forma de interação do ser humano com a natureza colabora para que esta seja vislumbrada tanto quanto um mero objeto, recurso, dotado de valor econômico, quanto como uma propriedade humana, em que o ser humano tem liberdade para gozar, dispor e utilizar conforme seus entendimentos e anseios. $\mathrm{O}$ afastamento do homem da natureza, colocando-a como algo à parte e à disposição do ser humano é possível de ser controlada por este, conforme explicam Ingo Wolfgang Sarlet e Tiago Fensterseifer²

até hoje marca a abordagem científica em quase todas as áreas do conhecimento, bem como para o processo de instrumentalização, apropriação e dominação da Natureza e dos recursos naturais, o que, em grande medida, tem nos conduzido ao atual estágio preocupante de degradação ambiental e mesmo de risco existência.

A visão quanto a forma de se entender os recursos naturais, juntamente com o modelo de desenvolvimento adotado pela humanidade no transcorrer dos séculos, desencadeou o atual cenário de crise ecológica global, colocando desafios para a humanidade que não haviam sido experimentados pela espécie humana desde seu surgimento no planeta.

Problemáticas como perda da diversidade biológica, crise hídrica, contaminação pelo uso de agrotóxicos e outros produtos químicos, má gestão dos resíduos sólidos, poluição atmosférica, mudança climática desafiam a ciência moderna, bem como as instituiçôes humanas, que se deparam com problemáticas de caráter global, ou seja, transfronteiriças, cujo efetivo enfrentamento demanda uma atuação conjunta e cooperativa de inúmeros atores internacionais e nacionais.

Ressalta-se que a crise ambiental afeta profundamente a diversidade biológica reduzindo, por consequência, o número de espécies e ocasionando o aumento das taxas de extinção. Estima-

1 OST, 1997 apud CAMPELLO, Lívia Gaigher Bósio; LIMA, Rafaela de Deus. O princípio da cooperação internacional em face às fronteiras planetárias. Revista Argumentum - RA, Marília, v. 19, n. 2, pp. 331-356, Mai.-Ago, 2018.

2 SARLET, Ingo Wolfgang; FENSTERSEIFER, Tiago. Direito ambiental: introduçáo, fundamentos e teoria geral. São Paulo: Saraiva, 2014, p. 120-121. 
se que apenas entre os anos de 1970 e 2014 houve uma redução média de $60 \%$ da população de vertebrados, enquanto - atualmente $-45 \%$ dos invertebrados terrestres, $34 \%$ dos invertebrados de água doce e $25 \%$ dos invertebrados marinhos encontram-se em risco de extinçãa ${ }^{3}$.

As consequências decorrentes dessas ações antrópicas repercutem em vários campos do conhecimento; ao serem percebidas pela geologia, instaurou-se o debate - em meados dos anos 2000 - acerca de uma nova época geológica denominada Antropoceno, em que o ser humano teria se transformado em um agente com capacidade de mudar a história e o rumo do planeta ${ }^{4}$.

Para Paul J. Crutzen e Eugene F. Stoermer:

a Terra, agora, deixou sua época geológica atual, o presente estado interglacial chamado de Holoceno. As atividades humanas se tornaram dominantes e profundas que rivalizam com as grandes forças da natureza e empurram a Terra para uma incógnita planetária ${ }^{5}$ (tradução nossa) $)^{6}$.

O Antropoceno, portanto, é a época da crise ecológica global e do ser humano enquanto força capaz de modificar o futuro do planeta. Nesse contexto, de modo paradoxal, o ser humano, responsável pela crise ecológica e a situação limítrofe vivenciada na atualidade, é o único que detém a capacidade de contê-la e revertê-la, reparando os seus erros, e protegendo a si mesmo e todas as formas de vida existentes? ${ }^{7}$.

O Antropoceno é o ponto de virada na história da humanidade, na história da vida e na história da própria Terra ${ }^{8}$, pois o ser humano é considerado como agente geológico capaz de transformar o planeta e colocá-lo em um novo caminho. As atividades humanas se tornaram dominantes e profundas ao ponto de rivalizar com as grandes forças da natureza e empurrar a Terra para uma incógnita planetária9

Com efeito, o desenvolvimento sustentável, enquanto meio para o alcance da sustentabilidade, deve considerar os limites estabelecidos pelo próprio planeta Terra, ou seja, importa atuar respeitando as fronteiras planetárias, com o propósito de que as açóes humanas e o processo de desenvolvimento não prejudiquem ainda mais o equilíbrio ecológico, ameaçado, por conseguinte a manutenção de todas as formas de vida existentes no planeta e interferindo no direito ao meio ambiente equilibrado inter e intrageracional.

Conciliar no desenvolvimento os três pilares da sustentabilidade ${ }^{10}$, ou seja, os pilares ambiental, social e econômico, é essencial para o bioma Pantanal.

3 UN. Sixth Global Environment Outlook. 2019.

4 CAMPELLO, Lívia Gaigher Bósio; LIMA, Rafaela de Deus. A sociedade de risco na nova época do Antropoceno: a aplicação da prevenção e da precaução para a gestão dos riscos ambientais. In: Anais do VII Congresso Nacional da FEPODI [Recurso eletrônico on-line] organização VII Congresso Nacional da FEPODI - São Paulo, 2019, p. 1337-1345.

5 STEFFEN, Will; CRUTZEN, Paul J.; MCNEILL, John. The Anthropocene: are Humans now overwhelming the Great Forces of Nature?Ambio, v. 36, n. 8, [S.1], 2007. n. p.

6 The term Anthropocene [...] suggests that the Earth has now left its natural geological epoch, the present interglacial state called the Holocene. Human activities have become so pervasive and profound that they rival the great forces of Nature and are pushing the Earth into planetary terra incognita. The Earth is rapidly moving into a less biologically diverse, less forested, much warmer, and probably wetter and stormier state.

7 CAMPELLO; LIMA, op. cit.

8 LEWS, Simon; MASLIN, Mark A. The Human Planet: how we created the Anthropocene.[S.l.]: Yale University Press, 2018.

9 STEFFEN; CRUTZEN; MACNEILL, op. cit, p.614.

10 ELKINGTON, John. Sustentabilidade, canibais com garfo e faca. São Paulo: M. Books do Brasil, 2012. 
A adoção para o bioma Pantanal do paradigma do desenvolvimento sustentável, de forma a buscar estabilizar os três pilares, é apta a minimizar os danos causados pela atuaçáo humana no meio ambiente.

\section{0 cenário ecológico atual do bioma pantanal}

O Direito ao meio ambiente ecologicamente equilibrado para as presentes e futuras geraçôes, norma positivada na Constituição Federal de 1988, em seu art. 22511, passa, necessariamente, pela proteção e preservação desse importante bioma que é o Pantanal.

Na América do Sul, o Pantanal se destaca por ser a maior planície contínua inundável continental do mundo, com cerca de $175 \mathrm{mil} \mathrm{km}{ }^{2}$, abrangendo partes dos territórios da Bolívia, do Paraguai e Brasil e possui alta relevância ambiental florística, faunística e biológica, amparada pelo regime atípico hidrológico, originária das regióes Cerrados, Amazônica e Chaco.

Vale ressaltar a relevância do bioma, pois é declarado Reserva da Biosfera ${ }^{12}$ e Patrimônio Mundial Natural ${ }^{13}$ pela UNESCO (Organização das Nações Unidas para a Educação, a Ciência e a Cultura).

Segundo a World Wide Fund for Nature (WWF) ${ }^{14}$, o bioma abriga 656 espécies de aves, 159 de mamíferos, 325 espécies de peixes, 98 de répteis, 53 de anfíbios e mais de 3,5 mil plantas. No Pantanal, há 10 sítios Ramsar ${ }^{15}$, áreas úmidas reconhecidas pela Convenção Internacional. Três deles ficam no Brasil: o Parque Nacional do Pantanal Matogrossense, a RPPN Sesc Pantanal e a RPPN Fazenda do Rio Negro ${ }^{16}$.

O bioma Pantanal possui uma área de $624.320 \mathrm{~km}^{2}$, aproximadamente $62 \%$ no Brasil, nos estados do Mato Grosso e Mato Grosso do Sul; 20\% na Bolívia, no estado de Santa Cruz e 18\% no Paraguai, nos estados do Alto Paraguai, Boqueron e Presidente Hayes ${ }^{17}$.

A relevância do bioma vai muito além dos números e estatísticas, pois o pantanal é responsável por sustentar serviços ambientais de extrema importância como a regulação do clima e inundação/seca, controle de fertilidade do solo, controle biológico, manutenção da biodiversidade, e fonte de água, alimentação e de matéria prima para a população, e também as principais atividades produtivas (agrícola e pecuária) que contribuem à economia da regiáo.

11 Art. 225. Todos têm direito ao meio ambiente ecologicamente equilibrado, bem de uso comum do povo e essencial à sadia qualidade de vida, impondo-se ao Poder Público e à coletividade o dever de defendê-lo e preservá- lo para as presentes e futuras geraçôes.

12 IMASUL. Comitê aprova criação de Prêmio para incentivar boas práticas na Reserva da Biosfera do Pantanal. Disponível em <https://www.imasul.ms.gov.br/Geral/reserva-da-biosfera/>. Acesso em 01 mai. 2021.

13 UNESCO. Pantanal Biosphere Reserve, Brazil. [online]. Disponível em <https://en.unesco.org/biosphere/ lac/pantanal>. Acesso em 22 jan. 2021.

14 WWF BRASIL. Pantanal. Disponível em <https://www.wwf.org.br/natureza_brasileira/areas_prioritarias/ pantanal/> Acesso em 05 out. 2020.

15 Zonas úmidas selecionadas pelo país contratante da Convenção de Ramsar (1971) consideradas representativas, raras ou únicas e de importância internacional para conservar a diversidade biológica.

16 MMA. Brasil, Bolívia e Paraguai juntos pelo Pantanal. Disponível em <https://www.mma.gov.br/informma/ item/14677-noticia-acom-2018-03-2903.html> Acesso em 07 mar 2021.

17 WWF BRASIL. Pantanal. Disponível em <https://www.wwf.org.br/natureza_brasileira/areas_prioritarias/ pantanal/> Acesso em 05 out. 2020. 
O Pantanal é um ecossistema de área úmida sempre em mudança entre ambientes aquáticos e terrestres. Outras regióes influenciam as inundaçóes, sendo relevante a região do planalto, pois as águas do planalto fluem em direçáo à depressão do Pantanal e ao atingir a planície pantaneira movem-se lentamente, inundando áreas marginais, que sustentam a diversidade biológica do Pantanal, num ecossistema dinâmico ante o influxo de microorganismos, invertebrados, partículas e nutrientes. É um sistema sazonal de fluxo de águas que permite o equilíbrio ecossistêmico do Pantanal, essencial para a manutenção da rica biodiversidade do bioma, permanecendo, geralmente, de maio a outubro, as terras secas com formação dos campos. O desmatamento tem sido observado na regiáo do Planalto, o que impacta o regime de águas ${ }^{18}$.

Vale salientar que esse regime de águas é essencial ao bioma e sua alteração interfere nos processos ecológicos, que já vêm sofrendo impacto da política de expansão agrícola na região do planalto, que se iniciou na década de 70 . Essas alteraçóes na região do planalto e no território do Bioma, inclusive com falta de preservação das áreas de preservação permanente e das Florestas Ripárias, alteram a dinâmica alimentar no bioma, impactando seriamente a biodiversidade do Pantanal, podendo em casos extremos de fogo provocar perda da biodiversidade, se atingir o banco de sementes.

Pode-se afirmar, portanto, que as zonas úmidas, como o Pantanal, apresentam uma latente fragilidade, pois intervençôes humanas realizadas de forma inadequada e irracional são suficientes para ocasionar sua degradação, refletindo, diretamente, no desenvolvimento sustentável, posto que suas atividades econômicas dependem, necessariamente, dos recursos naturais e condiçóes ecológicas fornecidas pelas áreas úmidas ${ }^{19}$.

Pesquisas realizadas pela $\mathrm{Embrapa}^{20}$ revelam que, nas últimas três décadas, o Pantanal vem sofrendo agressões pelo homem, praticadas não somente na planície, mas, principalmente, nos planaltos adjacentes. Atualmente, os impactos ambientais e socioeconômicos no Pantanal são muito evidentes, decorrentes da inexistência de um planejamento ambiental que garanta a sustentabilidade dos recursos naturais desse importante bioma.

Uma das causas dessa degradação é a expansão desordenada e rápida da agropecuária, com a utilização de pesadas cargas de agroquímicos, a exploraçáo de diamantes e de ouro nos planaltos, com utilização intensiva de mercúrio, que acarretam profundas transformaçóes regionais.

Dados divulgados pela ONG WWF-Brasil ${ }^{21}$ informam que $18 \%$ do Pantanal foi desmatado; dentre as causas de sua devastação estão a expansão das commodities, principalmente para a produção extensiva de gado. A parte alta da Bacia do Alto Paraguai (BAP), região com

18 ALHO, Cleber José Rodrigues; MAMEDE, Simone; BENITES, Maristela; ANDRADE, Bruna S.; SEPÚLVEDA, José J. O. Ameaças à biodiversidade do Pantanal Brasileiro pelo uso e ocupação da terra. Revista Ambiente \& Sociedade. São Paulo. Vol. 22, 2019.

19 DAROLD, Fernanda Ribeiro; IRIGARAY, Carlos Teodoro José Hugueney. A importância da preservação e conservação das áreas úmidas como mecanismo de efetivação do direito constitucional ao meio ambiente ecologicamente equilibrado para as futuras geraçóes. In: Revista Direito e Justiça: Reflexóes Sociojurídicas Santo Ângelo, v. 18, n. 31, p. 167-180, maio/ago. 2018.

20 EMBRAPA PANTANAL. Impactos ambientais e socioeconômicos no Pantanal. Disponível em <https:// www.embrapa.br/pantanal/impactos-ambientais-e-socioeconomicos-no-pantanal> Acesso em 15 abr 2021.

21 WWF BRASIL. Pantanal. [online] Disponível em <https://www.wwf.org.br/natureza_brasileira/areas_ prioritarias/pantanal/> Acesso em 05 mai. 2021. 


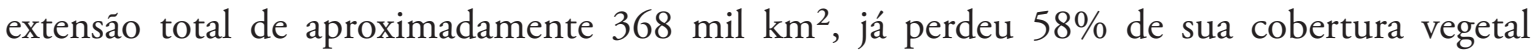
original, onde se concentra a maior parte das nascentes que alimentam o bioma.

Outro fator que merece destaque e cuidado é que, no Pantanal, vivem diversas comunidades indígenas e tradicionais, que conhecem o bioma e dele extraem sua sobrevivência, sendo uma fonte de oportunidades para a preservação e o seu desenvolvimento com base no uso dos conhecimentos tradicionais. Sendo assim, a degradação desordenada impacta diretamente nessas populações, que atuam na conservaçáo do bioma, ao mesmo passo que atividades econômicas também são lá realizadas, de maneira sustentável.

Nessa linha, os saberes tradicionais das populaçóes ribeirinhas do Pantanal, de ancestralidade indígena, são fundamentais na conservação do ecossistema, pois seguem regras de manejo dos recursos naturais que foram forjadas em uma cultura experimentada cotidianamente ao longo dos séculos, portanto, comprovadamente sustentável.

Assim, a conservação da biodiversidade do Pantanal é essencial para garantir às comunidades seu direito à vida digna e ao desenvolvimento, ao passo que garante à toda a sociedade seu direito ao meio ambiente ecologicamente equilibrado para fruição de sadia qualidade de vida.

Ademais, outro grande agravante da degradação desse relevante bioma é o aumento dos incêndios; segundo o Instituto Nacional de Pesquisas Espaciais (INPE), em notícia divulgada pela Agência Câmara de Notícias ${ }^{22}$, no ano de 2020 houve um aumento de $200 \%$ nos incêndios no Pantanal apenas no período entre 2019 e 2020. A notícia divulga, ainda, que o número de focos de incêndio já ultrapassou qualquer outro ano que se tenha registrado na série histórica, desde 1998, atingindo 23\% da área total do Pantanal. De 01 de janeiro de 2020 a 05 de outubro de 2020, o número de focos de incêndio no Pantanal atingiu a surpreendente quantia de 19.140, representando $11,04 \%$ do total no Brasil ${ }^{23}$.

Verifica-se, portanto, que esse bioma apresenta grande influência para a manutenção do equilíbrio ambiental, ecológico, biológico e hidrológico, evidenciando, portanto, a premente necessidade de protegê-lo e conservá-lo para as presentes e futuras geraçôes.

Como se pode observar, a necessidade de proteção jurídica desse bioma revela-se de extrema importância sob diversos aspectos, pois por um lado é um meio de efetivação do direito humano ao meio ambiente ecologicamente equilibrado para as geraçóes presentes e futuras, por outro, existem obrigaçóes internacionais assumidas pelos países que compartilham esse bioma transfronteiriço.

\section{A emergência da proteção jurídica internacional do bioma pantanal}

O caráter transnacional das problemáticas ambientais demanda, para seu enfrentamento, uma atuação planejada, cooperativa e solidária dos atores públicos e privados, nos mais diversos

22 HAJE, Lara; DOEDERLEIN, Natalia. Inpe confirma aumento de quase 200\% em queimadas no Pantanal entre 2019 e 2020. Agência Câmara de Notícias, Brasília, 30 de set. de 2020. Disponível em <https://www. camara.leg.br/noticias/696913-inpe-confirma-aumento-de-quase-200-em-queimadas-no-pantanal-entre2019-e-2020/> Acesso em: 04 mar. de 2021.

23 INPE. Programa Queimadas - Apoio. Disponível em <http:/queimadas.dgi.inpe.br/queimadas/ bdqueimadas/\#> Acesso em 05 mai 2021. 
planos, partindo desde uma esfera local, regional e nacional até a esfera internacional. Para uma melhor compreensão da relevância desta ação cooperativa e, por conseguinte, da cooperação internacional:

o princípio [da cooperação internacional] deve ser interpretado sob a luz do princípio da solidariedade internacional ambiental, vez que serve como instrumento à concretizaçáo do direito de todos, inclusive das futuras geraçóes, à qualidade de vida e ao meio ambiente ecologicamente equilibrado ${ }^{24}$.

Com efeito, o bioma Pantanal é transfronteiriço, ultrapassando os limites territoriais impostos pelo ser humano e se fazendo presente nos territórios de Brasil, Paraguai e Bolívia, ainda que em cada um desses países adote características diferentes pela dependência da conexão com outros ecossistemas. Dessa forma, frente à ubiquidade desse bem ambiental, passa-se a exigir respostas na esfera internacional, numa perspectiva de cooperaçáo internacional, para assegurar sua efetiva proteção.

Nessa esteira de ideias, o Direito Internacional do Meio Ambiente (DIMA) busca alcançar essa tutela internacional, consolidando documentos multilaterais de grande relevância que também influenciam o ordenamento jurídico nacional. Estabelecida em fevereiro de 1971, na cidade iraniana de Ramsar, a Convenção sobre Zonas Úmidas de Importância Internacional, mais conhecida como Convençáo de Ramsar, está em vigor desde 21 de dezembro de 1975. O tratado foi ratificado por governantes de 18 países, no dia 3 de fevereiro de $1971^{25}$. Atualmente, são 170 países signatários da Convençáo, contando com 2.403 sítios designados que abrangem uma área de 254.307.159 hectares.

Dessa forma, considerando as mais diversas intervençôes humanas degradantes nas áreas úmidas, a Convenção de Ramsar busca tutelar e evidenciar a importância dessas zonas sob os aspectos de diversidade biológica e do desenvolvimento sustentável, sendo evidente e necessária a proteção jurídica dessas áreas.

É louvável que a Convenção de Ramsar determina marcos para ações nacionais e para a cooperação entre países com o objetivo de promover a conservaçáo e o uso racional de áreas úmidas no mundo. No entanto, considerando que o Pantanal é a maior área inundável intercontinental do globo, necessário se faz que os países que hospedam o Pantanal cooperem, de forma harmônica, para a sua preservaçáo, proteção e seu uso sustentável, pautando suas açóes no reconhecimento da importância ecológica e do valor social, econômico, cultural, científico e recreativo desse Bioma, sempre privilegiando o desenvolvimento sustentável desse bioma.

Diante da importância desse bioma transfronteiriço, emerge a necessidade de uma proteção jurídica internacional que considere as peculiaridades desse ecossistema e que esteja apto a disciplinar a exploraçáo dos seus recursos naturais, primando pela sustentabilidade e cooperação entre os países onde está localizado o Pantanal, sempre considerando a vasta biodiversidade que o caracteriza e sua importância para o desenvolvimento local, regional e nacional.

24 CAMPELLO, Lívia Gaigher Bósio. Princípios do Direito Internacional do Meio Ambiente. In: CAMPELLO, Lívia Gaigher Bósio; DE SOUZA, Maria Claudia da Silva Antunes; PADILHA, Norma Sueli. Direito Ambiental no Século XX: efetividade e desafios. vol. 3. Belo Horizonte: Arraes Editores, 2014, p. 273.

25 RAMSAR CONVENTION SECRETARIAT. An Introduction to the Convention on Wetlands. Gland, Switzerland: Ramsar Convention Secretariat, 2016. 
Nesse sentido, o compromisso entre os governos do Brasil, Bolívia e Paraguai para a cooperação com foco no Pantanal foi assumido em 2015, em reunião da Convenção de Ramsar. Uma resolução aprovada enfatizou o importante papel da conservação e do desenvolvimento sustentável da região, para a manutenção das funções dos ecossistemas nos países da Bacia do Prata. Desde então, os três países passaram a estudar áreas de interesses comuns e definir medidas para o desenvolvimento sustentável da regiáo, em um trabalho que culminou na assinatura de uma Declaração Trinacional ${ }^{26}$.

Na sequência, ocasião do oitavo Fórum Mundial da Água, em março de 2018, Bolívia, Brasil e Paraguai assinaram uma declaração conjunta para o desenvolvimento sustentável do bioma pantanal. A Declaração para a Conservação, Desenvolvimento Integral e Sustentável do Pantanal (2018) forma um conjunto de diretrizes para uma gestáo trinacional integrada do bioma pantaneiro. Com efeito, essa Declaração promove a integração de medidas para o bioma, tratando, com destaque, a gestáo dos recursos hídricos, mas com olhar voltado à conservação de ecossistemas, áreas úmidas, biodiversidade e conectividade.

A Declaração conjunta envolve o respeito aos povos do Pantanal e as açóes propostas orientam os diversos usos dos recursos hídricos da regiáo. As medidas incluem o controle da poluição, o fortalecimento da governança da água com foco nos ecossistemas, a adoção de sistemas produtivos resilientes para reduzir os efeitos da mudança do clima e a ampliação do conhecimento científico ${ }^{27}$.

A despeito das intençóes expostas nessa declaração, avanços estão sendo requeridos para se alcançar uma visáo integral do bioma Pantanal, o fortalecimento dos mecanismos de cooperação internacional e a implementação eficaz do desenvolvimento sustentável da região (social, econômico e ambiental) também por se tratar de um recurso natural transfronteiriço, nos termos também delineados pelo Tratado da Bacia do Prata (1969), o que demanda estudos acerca das medidas legais e institucionais no Brasil, Paraguai e Bolívia na proteção do bioma Pantanal.

Por essa razão, é patente a necessidade de se aprofundar a cooperação internacional entre os países onde se localiza o pantanal para alinharem suas legislaçóes na busca de uma ampla proteção jurídica desse importante bioma transfronteiriço.

\section{A cooperaçáo internacional para a proteçáo do bioma pantanal: análise das Constituiçóes de Brasil, Bolívia e Paraguai}

A necessidade de cooperação entre os Estados em busca do bem comum se revela de extrema importância para a consagração de Direitos Humanos.

Segundo Häberle,

'Estado Constitucional Cooperativo' é o Estado que justamente encontra a sua identidade também no Direito Internacional, no entrelaçamento das relaçóes internacionais e supranacionais, na percepção da cooperação e responsabilidade internacional, assim

26 MMA. Brasil, Bolívia e Paraguai juntos pelo Pantanal. Disponível em <https://www.mma.gov.br/informma/ item/14677-noticia-acom-2018-03-2903.html> Acesso em 07 mar 2021.

27 Ibid. 
como no campo da solidariedade. Ele corresponde, com isso, à necessidade internacional de políticas de paz $^{28}$.

O autor ainda observa que o Estado Constitucional Cooperativo trata, ativamente, da questão de outros Estados, de instituiçôes internacionais e supranacionais e dos cidadãos estrangeiros: sua abertura ao meio é uma abertura ao mundo (cf. art. $4^{\circ}$ da Constituição do Jura). A cooperação realiza-se política e juridicamente. Ela é, sobretudo, um momento de configuração. O Estado Constitucional Cooperativo corresponde ao desenvolvimento de um Direito Internacional Cooperativo. ${ }^{29}$

Transpondo o ideal de um Estado Constitucional Cooperativo para as questóes ligadas à proteção do meio ambiente, verifica-se que, diante da proporção tomada pela crise ecológica vivenciada, a conservação do meio ambiente se transforma em um objetivo global, comum a todos os Estados, e essencial ao bem-estar humano, "constituindo um vínculo solidário a todos os membros da comunidade internacional" 30 .

A ideia de solidariedade e responsabilidade é essencial no enfrentamento da crise ecológica e para a compreensão da relevância da cooperação internacional. Nesse sentido, a solidariedade "expressa a necessidade formal de coexistência do ser humano em um corpo social" 31 , sendo necessária a existência de vínculos de fraternidade para a efetivação dos direitos ecológicos ${ }^{32}$.

Por conseguinte, a ideia de um patrimônio comum da humanidade também toca de forma direta a questão ambiental, pois busca dar a dimensão de importância dos bens ambientais de forma alijada de uma perspectiva individualista, mas, acima de tudo, solidária e compartilhada entre todos ${ }^{33}$. Desse modo, Ingo Wolfgang Sarlet e Tiago Fensterseifer ${ }^{34}$ evidenciam que há, além da responsabilidade na esfera moral, também a necessidade de imposição de responsabilidades (deveres e obrigaçôes) no campo jurídico, com o propósito de frear o ímpeto destrutivo que tem nos guiado nos últimos séculos.

Nesse panorama, os Estados solidários - e a sociedade em geral - têm uma responsabilidade comum, tanto pelas consequências da crise ecológica, quanto pela proteção ambiental. Essa concepção é reforçada no Preâmbulo da Declaração de Estocolmo sobre o Meio Ambiente, o qual afirma que:

Para se chegar a esta meta [a defesa e melhoramento do meio ambiente humano para as geraçóes presentes e futuras] será necessário que cidadãos e comunidades, empresas e instituiçóes, em todos os planos, aceitem as responsabilidades que possuem e que todos eles participem equitativamente, nesse esforço comum ${ }^{35}$.

Portanto, diante do caráter transnacional das problemáticas ambientais, o seu enfrentamento demanda uma atuação planejada, cooperativa e solidária dos atores públicos e

28 HÄBERLE, Peter. Estado Constitucional Cooperativo. Tradução de Marcos Augusto Maliska e Elisete Antoniuk. Rio de Janeiro: Renovar, 2007, p. 4.

29 Ibid, p. 5-8.

30 CAMPELLO, op. cit. p. 271.

31 SARLET, Ingo Wolfgang; FENSTERSEIFER, Tiago. Direito ambiental: introduçáo, fundamentos e teoria geral. São Paulo: Saraiva, 2014, p. 91

32 Ibid.

33 Ibid.

34 Ibid.

35 ONU. Declaraçáo de Estocolmo sobre o Meio Ambiente Humano. Estocolmo, 1972. 
privados, nos mais diversos planos, partindo desde uma esfera local, regional e nacional até a esfera internacional. Para uma melhor compreensão da relevância desta ação cooperativa e, por conseguinte, da cooperaçáo internacional:

o princípio [da cooperação internacional] deve ser interpretado sob a luz do princípio da solidariedade internacional ambiental, vez que serve como instrumento à concretização do direito de todos, inclusive das futuras geraçôes, à qualidade de vida e ao meio ambiente ecologicamente equilibrado ${ }^{36}$.

É importante destacar que a cooperação internacional foi consagrada no direito internacional ambiental na Declaração de Estocolmo sobre o Meio Ambiente (1972), sendo prevista tanto em seu Preâmbulo quanto nos Princípios, com destaque aos princípios $22^{37}$ - que se preocupa com os danos ambientais ocorridos fora da jurisdição de um Estado - e $24^{38}$ - que impóe o dever do Estado de cooperar - bem como o princípio $12^{39}$, que faz previsão a uma assistência técnica e financeira internacional para auxiliar os países em desenvolvimento.

Nesse contexto, afirma-se que tal abordagem, em relação à cooperação internacional do meio ambiente, consiste no surgimento do "Direito Internacional da Cooperação", regendo um novo tipo de relaçôes internacionais, voltadas para o interesse comum da humanidade, bem como sua sobrevivência ao se preocupar com a preservação dos recursos naturais.

Posteriormente, a Declaração do Rio sobre Meio Ambiente e Desenvolvimento (1992) colocou a cooperação internacional como instrumento indispensável para a efetivação do desenvolvimento sustentável, estando presente nos Princípios 5, 7, 12, 13, 14, 18, 19 e 27, além de também ser contemplada na Agenda 21, com destaque aos Capítulos 2, 16, 17, 20, 31, 34 e 37. A preocupação com a cooperação internacional fica evidente, pois a Declaração do Rio sobre Meio Ambiente e Desenvolvimento (1992) elenca dentre seus objetivos:

[...] estabelecer uma nova e justa parceria global mediante a criação de novos níveis de cooperação entre os Estados, os setores-chaves da sociedade e os indivíduos, trabalhando com vistas à conclusão de acordos internacionais que respeitem os interesses de todos e protejam a integridade do sistema global de meio ambiente e desenvolvimento, reconhecendo a natureza integral e interdependente da Terra, nosso $\operatorname{lar}^{40}$.

Ainda que a cooperação internacional encontre previsão em inúmeros princípios da Declaração do Rio e capítulos da Agenda 21, insta destacar o Princípio $27^{41}$ que, embora bastante

36 CAMPELLO, op. cit. p. 273.

37 Os Estados devem cooperar para continuar desenvolvendo o direito internacional no que se refere à responsabilidade e à indenizaçáo às vítimas da poluição e de outros danos ambientais que as atividades realizadas dentro da jurisdição ou sob o controle de tais Estados causem à zonas fora de sua jurisdição.

38 Todos os países, grandes e pequenos, devem ocupar-se com espírito de cooperação e em pé de igualdade das questôes internacionais relativas à proteção e melhoramento do meio ambiente. É indispensável cooperar para controlar, evitar, reduzir e eliminar eficazmente os efeitos prejudiciais que as atividades que se realizem em qualquer esfera, possam Ter para o meio ambiente,, mediante acordos multilaterais ou bilaterais, ou por outros meios apropriados, respeitados a soberania e os interesses de todos os estados.

39 Recursos deveriam ser destinados para a preservação e melhoramento do meio ambiente tendo em conta as circunstâncias e as necessidades especiais dos países em desenvolvimento e gastos que pudessem originar a inclusão de medidas de conservação do meio ambiente em seus planos de desenvolvimento, bem como a necessidade de oferecer-lhes, quando solicitado, mais assistência técnica e financeira internacional com este fim.

40 ONU. Declaraçáo do Rio sobre Meio Ambiente e Desenvolvimento. Rio de Janeiro, 1992.

41 Os Estados e os povos devem cooperar de boa fé e imbuídos de um espírito de parceria para a realização dos princípios consubstanciados nesta Declaração, e para o desenvolvimento progressivo; do direito internacional no campo do desenvolvimento sustentável. 
discreto na estrutura geral da Declaração do Rio, introduziu vários conceitos inovadores no direito internacional e na governança, com foco na relaçáo de cooperaçáo bem como, inspirou uma ampla gama de projetos e parcerias para o desenvolvimento sustentável. Em um primeiro momento, é possível ter a concepção de que o princípio supramencionado busca meramente reiterar o que foi afirmado nos demais dispositivos da Declaraçáo do Rio. Contudo, por meio de uma análise mais aprofundada, constata-se que o Princípio 27 não consiste apenas em mais um postulado normativo, mas em uma diretriz para a implementação da Declaração do Rio como um todo ${ }^{42}$.

Nesse aspecto, houve o reconhecimento - no princípio 27 - de uma responsabilidade compartilhada para a efetivação dos demais princípios, manifestada na cooperação entre os Estados e os povos. Consequentemente, a implementação operacional deste princípio ocasionou a emergência de programas e projetos, objetivando a efetivação da Declaração do Rio ${ }^{43}$ e também a estimulaçáo do desenvolvimento do direito internacional no que concerne ao desenvolvimento sustentável.

Posteriormente, em 2012, na Conferência das Naçôes Unidas sobre o Desenvolvimento Sustentável (Rio+20), no documento O Futuro que Queremos (2012), foi reafirmado o compromisso de fortalecimento da cooperaçáo internacional com o objetivo de enfrentar os desafios decorrentes do desenvolvimento sustentável, em diversas perspectivas, bem como a relevância desta ferramenta nos acordos ambientais multilaterais.

Atualmente, a cooperação internacional também se encontra presente nos Objetivos do Desenvolvimento Sustentável (ODS), mais especificamente no Objetivo 17 que almeja "fortalecer os meios de implementação e revitalizar a parceria global para o desenvolvimento sustentável”, demonstrando que os ODS só serão realizados mediante um compromisso renovado de cooperação entre a comunidade internacional e uma parceria global ampla que inclua todos os setores interessados e as pessoas afetadas pelos processos de desenvolvimento.

Os meios de implementação e as parcerias para o desenvolvimento sustentável são vitais para o crescimento sustentável e para o desenvolvimento sustentável das naçôes. O ODS 17 propóe o caminho para a realização efetiva da Agenda 2030 por todos os países, e a cooperação de esforços na arena internacional é essencial para isso. A Cooperação Sul-Sul e triangular, a transferência de tecnologia, o intercâmbio de dados e capital humano, bem como a assistência oficial ao desenvolvimento são alguns meios para o alcance dos ODS (Objetivo 17 da Agenda 2030). Neste objetivo, há a previsão do melhoramento da cooperação Norte-Sul, Sul-Sul e triangular regional e internacional, assim como o aprimoramento do acesso à ciência, tecnologia $\mathrm{e}$ inovação, aumentando o compartilhamento de conhecimentos de forma mutuamente acordada, por meio de uma melhor coordenação de mecanismos já existentes.

Com efeito, frente à importância da cooperação internacional para lidar com questóes transfronteiriças e para implementar as disposiçôes estabelecidas pelos documentos de proteção do meio ambiente bem como pelos objetivos da Agenda 2030, esses mecanismos apresentam grande relevância em prol da conservação e utilização responsável e sustentável das terras

42 VIÑUALES, Jorge E. The Rio Declaration on Environment and Development: a commentary. United Kingdom: Oxford University Press, 2015.

43 Ibid. 
úmidas e seus recursos. Por conseguinte, a Convenção de Ramsar sobre Zonas Úmidas elenca a cooperação como um dos instrumentos a ser utilizado na proteção dessas áreas.

Com efeito, o Pantanal se insere nos limites fronteiriços do Brasil, Paraguai e Bolívia e para conservação do Bioma é essencial a cooperação entre esses países, o que já restou reconhecido na Declaração para a Conservação, Desenvolvimento Integral e Sustentável do Pantanal (2018), documento internacional de grande relevância para a sobrevivência do bioma que reforça os compromissos com os Objetivos de Desenvolvimento Sustentável da Agenda 2030 da ONU, incluindo ações de cooperação transfronteiriça, com a Convenção de Ramsar (1971) como marco para ação nacional e cooperação internacional em prol da conservação e uso racional das áreas úmidas e seus recursos, a responsabilidade de promover o desenvolvimento sustentável intra e intergeracional e os objetivos da Convenção de Diversidade Biológica (1992).

O documento ressalta o necessário diálogo permanente entre os Estados fronteiriços, com a busca de instrumentos institucionais para promover o avanço de uma visão integral para o desenvolvimento sustentável do Pantanal, garantindo a sustentabilidade dos recursos hídricos e biomas transfronteiriços. No caso do Pantanal, reconhece sua complexidade e dinamicidade e sua importância como polo de desenvolvimento transfronteiriço em que estão sendo expandidas as atividades produtivas, em uma região com intensa dependência de recursos hídricos, cujo desequilíbrio das vazóes ecológicas acarretaria prejuízos inclusive às atividades econômicas da Bacia do Prata, o que demonstra sua interconectividade.

Ante a relevância do Bioma, é importante incrementar a cooperação internacional entre Brasil, Bolívia e Paraguai, com açóes articuladas e gestão integrada da Bacia do Paraguai. O grande desafio para o desenvolvimento sustentável é que o caminho de exercícios de atividade produtiva no Bioma Pantanal se realize com medidas de proteção da biodiversidade e da área úmida, incentivando práticas produtivas sustentáveis e adequadas à resiliência.

Nesse sentido, o fortalecimento das políticas nacionais é essencial nesse processo, originando-se de um relacionamento internacional firmado no diálogo e cooperação que sirvam como base às políticas e marcos normativos nacionais. Nesse sentido, as constituiçóes do Brasil, Bolívia e Paraguai se alinham.

A Constituição Federal de 1988, no art. 225, dispóe ser direito de todos o meio ambiente ecologicamente equilibrado, que deve ser garantido às presentes e às futuras geraçôes. Para tanto é necessário que o Estado busque a preservação e restauração dos processos ecológicos essenciais, promovendo o manejo ecológico de espécies e ecossistemas e exerça o controle da produção, comercialização e emprego de técnicas, métodos e substâncias que comportem risco ao meio ambiente.

Sobre a relevância dessa nova ordem ambiental, Herman Benjamin pontua que o seu conteúdo a aproxima do conceito de cunho teórico-abstrato do Estado de Direito Ambiental e marca a instauração de uma nova ordem. Nas palavras do autor:

Coube à Constituição - do Brasil, mas também de muitos outros países - repreender e retificar o velho paradigma civilístico, substituindo-o, em boa hora, por outro mais sensível à saúde das pessoas (enxergadas coletivamente), às expectativas das futuras geraçôes, à manutenção das funçóes ecológicas, aos efeitos negativos a longo prazo da exploração predatória dos recursos naturais, bem como aos benefícios tangíveis e intangíveis do seu uso-limitado (e até náo uso). O universo dessas novas ordens constitucionais, afastando- 
se das estruturas normativas do passado recente, não ignora ou despreza a natureza, nem é a ela hostil ${ }^{44}$.

Ao estabelecer os princípios da ordem econômica, no art. 170, a CRFB traz como seu fim assegurar a todos vida digna com justiça social, estabelecendo como princípios a soberania nacional, a defesa do meio ambiente e a redução das desigualdades sociais e regionais, a busca do pleno emprego e a função social das propriedades. O Estado é competente para normatizar e regular as atividades econômicas e deverá estabelecer, por lei, as diretrizes para o planejamento do desenvolvimento nacional equilibrado, incorporando e compatibilizando os planos nacionais e regionais de desenvolvimento, consoante o art. 174. Ao se analisar as disposiçóes sobre a ordem econômica e seus princípios, é possível afirmar que o Brasil, no texto constitucional, faz opção pelo desenvolvimento sustentável.

A soberania nacional, princípio da ordem econômica e fundamento da República Federativa do Brasil, é exercida com observância do princípio da cooperação entre os povos para o progresso da humanidade em suas relaçôes internacionais. E, considerando o objetivo de se construir uma sociedade livre, justa e solidária, também se verifica o pilar social que deve ser observado no desenvolvimento. Assim, o caminho para o desenvolvimento sustentável pavimentado no Brasil implica em reconhecimento simultâneo dos pilares ambiental, social e econômico.

A Constituição da Bolívia, ao passo em que traz em seu texto, no art. $33^{45}$, o direito ao meio ambiente saudável, protegido e equilibrado para presentes e futuras geraçôes, e de outros seres para desenvolver-se de forma normal e permanente, também traz em seu art. $9^{\circ}, 6^{46}$, que é função do Estado garantir o aproveitamento responsável dos recursos naturais, impulsionando a industrialização através do desenvolvimento e do fortalecimento da base produtiva em seus diferentes níveis e dimensôes, com obrigação a todas as organizações econômicas de defender o meio ambiente, consoante art. 312 $2^{47}$. A funçáo do Estado na economia, consoante art. 316, 648, consiste na promoção da industrialização com base em recursos renováveis e não renováveis com base no respeito ao meio ambiente e na geração de emprego e insumos econômicos e sociais para a população.

44 BENJAMIN, Antonio Herman de Vasconcellos e. Direito constitucional ambiental brasileiro. In: CANOTILHO, José Joaquim Gomes; LEITE, José Rubens Morato (Org.). Direito constitucional ambiental brasileiro. São Paulo: Saraiva, 2007. parte II, p. 57-130.

45 Artículo 33. Las personas tienen derecho a un medio ambiente saludable, protegido y equilibrado. El ejercicio de este derecho debe permitir a los individuos y colectividades de las presentes y futuras generaciones, además de otros seres vivos, desarrollarse de manera normal y permanente.

46 Artículo 9. Son fines y funciones esenciales del Estado, además de los que establece la Constitución y la ley:

[...]

6. Promover y garantizar el aprovechamiento responsable y planificado de los recursos naturales, e impulsar su industrialización, a través del desarrollo y del fortalecimiento de la base productiva en sus diferentes dimensiones y niveles, así como la conservación del medio ambiente, para el bienestar de las generaciones actuales y futuras.

47 Artículo. 312

III. Todas las formas de organización económica tienen la obligación de proteger el medio ambiente.

48 Artículo 316. La función del Estado en la economía consiste en:

[...]

6. Promover prioritariamente la industrialización de los recursos naturales renovables y no renovables, en el marco del respeto y protección del medio ambiente, para garantizar la generación de empleo y de insumos económicos y sociales para la población. 
Do narrado, é possível se verificar que a Bolívia guarda em sua Constituição a necessidade de se trilhar pelo caminho do desenvolvimento sustentável, com base nos pilares ambiental, econômico e social. A preocupação com o patrimônio ambiental o inseriu como de interesse público, o que se confere pela redação dos artigos $342^{49}$ e $343^{50}$ da Constituição Boliviana, que ainda considerou os recursos naturais como estratégicos para o desenvolvimento sustentável do país, com conservação e aproveitamento para o benefício da população como responsabilidade do Estado, com exercício da soberania, para aproveitamento dos recursos naturais e da biodiversidade de maneira sustentável, mantendo-se o equilíbrio do meio ambiente.

Já a Constituição do Paraguai, em seu art. $70^{51}$, reconhece o direito a um ambiente saudável e equilibrado a todas as pessoas, com objetivos prioritários e de interesse social a preservaçáo, conservação e a recomposição e melhora do ambiente, conciliando-o ao desenvolvimento humano integral. Considerando suas relações externas, o Paraguai, em condições de igualdade com outros Estados, admite um ordenamento jurídico supranacional que garanta os direitos humanos e a cooperação e o desenvolvimento econômico e social, conforme art. 145:

\section{Artículo 145 - DEL ORDEN JURIDICO SUPRANACIONAL}

La República del Paraguay, en condiciones de igualdad con otros Estados, admite un orden jurídico supranacional que garantice la vigencia de los derechos humanos, de la paz, de la justicia, de la cooperación y del desarrollo, en lo político, económico, social y cultural.

Dichas decisiones sólo podrán adoptarse por mayoría absoluta de cada Cámara del Congreso

No tocante à política econômica e de promoção do desenvolvimento social, econômico e cultural, sua promoção pelo Estado observará a utilização dos recursos disponíveis objetivando um crescimento ordenado e sustentado, que se fomentará com programas globais que coordenem a atividade econômica nacional, consoante art. $176^{52}$. A Carta Paraguaia, portanto, concilia os pilares do desenvolvimento sustentável, ambiental, social e econômico.

Como se pode inferir, o caminho para a proteção jurídica internacional e para o desenvolvimento sustentável do Pantanal encontra voz nas Constituiçóes dos países que se encontram em seu limite transfronteiriço, o que pavimenta o espaço da cooperação, que também é incentivada no ordenamento interno dos três países fronteiriços em que o bioma se encontra de forma que, sob o prisma do desenvolvimento sustentável, as diferenças internas referentes à forma como se disciplina o meio ambiente não se mostram relevantes

49 Artículo 342. Es deber del Estado y de la población conservar, proteger y aprovechar de manera sustentable los recursos naturales y la biodiversidad, asi como mantener el equilibrio del medio ambiente.

50 Artículo 343. La población tiene derecho a la participación en la gestión ambiental, a ser consultado e informado previamente sobre decisiones que pudieran afectar a la calidad del medio ambiente.

51 Artículo 7 - DEL DERECHO A UN AMBIENTE SALUDABLE

Toda persona tiene derecho a habitar en un ambiente saludable y ecológicamente equilibrado. Constituyen objetivos prioritarios de interés social la preservación, la conservación, la recomposición y el mejoramiento del ambiente, así como su conciliación con el desarrollo humano integral. Estos propósitos orientarán la legislación y la politica gubernamental pertinente.

52 Artículo 176 - DE LA POLITICA ECONOMICA Y DE LA PROMOCION DEL DESARROLLO

La politica económica tendrá como fines, fundamentalmente, la promoción del desarrollo económico, social y cultural. El Estado promoverá el desarrollo económico mediante la utilización racional de los recursos disponibles, con el objeto de impulsar un crecimiento ordenado y sostenido de la economía, de crear nuevas fuentes de trabajo y de riqueza, de acrecentar el patrimonio nacional y de asegurar el bienestar de la población. El desarrollo se fomentará con programas globales que coordinen y orienten la actividad económica nacional. 
Diante desses desafios, a eficácia da proteção jurídica internacional do Pantanal tem suas bases nas leis de cada país, partindo de suas Constituições Federais que possuem os predicados necessários à garantia do meio ambiente saudável e pautado no desenvolvimento sustentável. A despeito de os governos do Brasil, Bolívia e Paraguai não possuírem normatização específica atinente ao Pantanal, a cooperação entre esses países é evidente, corroborada pela Declaração para a Conservação, Desenvolvimento Integral e Sustentável do Pantanal (2018), sendo um primeiro passo significativo para a contribuição e fundamentação de diretrizes com o objetivo de melhor preservar esse bioma.

\section{Conclusáo}

A crise ecológica global representa um dos principais desafios a ser enfrentado pela humanidade no século XXI. As problemáticas que lhe são inerentes tornam-se mais complexas frente ao seu caráter transfronteiriço, o que demanda uma visão holística que busque soluçôes coordenadas tanto no contexto internacional quanto nacional, regional e local.

Dentre as inúmeras questôes ambientais, destaca-se a proteção jurídica internacional do bioma Pantanal. Essa área é caracterizada por complexos processos ecológicos e pela rica biodiversidade, além disso, apresentam grande relevância para a população local, sobretudo por se tratar de um bioma transfronteiriço, estando presente em parte dos territórios de Brasil, Bolívia e Paraguai. Contudo, atualmente, o Pantanal sofre com grande perda e degradação, incentivada pela política de expansão agrícola na região do planalto, causando significativas alteraçóes na regiáo do planalto e no território do Bioma, inclusive com falta de preservação das áreas de preservação permanente, especialmente pelo aumento das incêndios que devastou grande parte dessa área úmida, o que se distancia da visão de desenvolvimento sustentável estimulada pela ONU em diversos tratados e convençôes, evidenciando a necessidade de buscar sua tutela no ordenamento jurídico internacional e nacional.

Diante da emergência em se proteger as áreas úmidas como o Pantanal, foi estabelecido um regime de proteção dessas áreas, o qual tem como marco a Convenção de Ramsar de 1971 que, atualmente, conta com 170 países signatários, entre eles Brasil, Bolívia e Paraguai.

Para a concretização do objetivo da Convenção, importa buscar a tutela dessas áreas no paradigma do desenvolvimento sustentável, viabilizando a sua proteção ambiental e também considerando as questôes sociais das populaçôes tradicionais e indígenas que vivem nessas áreas. Nesse contexto, a cooperação internacional apresenta-se como mecanismo de grande relevância na proteção dessas zonas pois, devido ao seu caráter transfronteiriço, a sua efetiva tutela demanda e a atuação multilateral de inúmeros atores no cenário internacional, tanto Estados quanto a população, organizaçóes internacionais governamentais e não-governamentais, bem como os atores privados.

A despeito da Convenção de Ramsar determinar marcos para açôes nacionais e para a cooperação entre países com o objetivo de promover a conservação e o uso racional de áreas úmidas no mundo, é necessário que os países que hospedam o Pantanal cooperem, de forma harmônica, para a sua preservação, proteção e seu uso sustentável, pautando suas açóes no reconhecimento da importância ecológica e do valor social, econômico, cultural, científico e recreativo desse Bioma. 
Importante ressaltar que as Constituições Federais dos três países onde está situado o Pantanal possuem todos os predicados necessários à efetivação de açôes voltadas à proteção do bioma.

Nesse sentido, a Declaração para a Conservação, Desenvolvimento Integral e Sustentável do Pantanal, firmada por Brasil, Bolívia e Paraguai, em 2018, representa um grande avanço na busca de se tutelar juridicamente o Pantanal. Da mesma forma, revela-se de extrema importância para a pavimentação de uma proteção jurídica cooperativa entre essas naçóes, já que o bioma não se limita às jurisdiçóes das fronteiras físicas entre esses países. Além disso, reforça os valores previstos em diversos documentos internacionais, dando especial atenção aos recursos hídricos.

A declaração expõe as boas intenções de Brasil, Bolívia e Paraguai em proteger, preservar e promover o uso sustentável dos recursos naturais do bioma Pantanal. No entanto, ainda se mostra necessária uma ação cooperativa entre esses países que enfatize a proteção do bioma, considerando as diversas nuances e características próprias do Pantanal, sempre tendo como paradigma o desenvolvimento sustentável. Com efeito, muito há que se refletir, discutir e concretizar para a efetiva tutela internacional desse patrimônio ambiental, o que somente será possível com a cooperação internacional entre esses países.

\section{Referências}

ALHO, Cleber José Rodrigues; MAMEDE, Simone; BENITES, Maristela; ANDRADE, Bruna S.; SEPÚLVEDA, José J. O. Ameaças à biodiversidade do Pantanal Brasileiro pelo uso e ocupação da terra. Revista Ambiente \& Sociedade. São Paulo. Vol. 22, 2019

BENJAMIN, Antonio Herman de Vasconcellos e. Direito constitucional ambiental brasileiro. In: CANOTILHO, José Joaquim Gomes; LEITE, José Rubens Morato (Org.). Direito constitucional ambiental brasileiro. São Paulo: Saraiva, 2007. parte II, p. 57-130.

CAMPELLO, Lívia Gaigher Bósio. Princípios do Direito Internacional do Meio Ambiente. In: CAMPELLO, Lívia Gaigher Bósio; DE SOUZA, Maria Claudia da Silva Antunes; PADILHA, Norma Sueli (Org.). Direito Ambiental no Século XX: efetividade e desafios. vol. 3. Belo Horizonte: Arraes Editores, 2014.

CAMPELLO, Lívia Gaigher Bósio; LIMA, Rafaela de Deus. A sociedade de risco na nova época do Antropoceno: a aplicação da prevenção e da precaução para a gestão dos riscos ambientais. Anais do VII Congresso Nacional da FEPODI [Recurso eletrônico on-line] organização VII Congresso Nacional da FEPODI - São Paulo, 2019, p. 1337-1345.

CAMPELLO, Lívia Gaigher Bósio; LIMA, Rafaela de Deus. O princípio da cooperação internacional em face às fronteiras planetárias. Revista Argumentum - RA, Marília, v. 19, n. 2, pp. 331-356, Mai.-Ago, 2018.

DAROLD, Fernanda Ribeiro; IRIGARAY, Carlos Teodoro José Hugueney. A importância da preservação e conservação das áreas úmidas como mecanismo de efetivação do direito constitucional ao meio ambiente ecologicamente equilibrado para as futuras geraçóes. Revista 
Direito e Justiça: Reflexóes Sociojurídicas - Santo Ângelo, v. 18, n. 31, p. 167-180, maio/ago. 2018.

DECLARAÇÃO para a conservaçâo, desenvolvimento integral e sustentável do pantanal, 2018.

ELKINGTON, John. Sustentabilidade, canibais com garfo e faca. São Paulo: M. Books do Brasil, 2012.

EMBRAPA PANTANAL. Impactos ambientais e socioeconômicos no Pantanal. Disponível em <https://www.embrapa.br/pantanal/impactos-ambientais-e-socioeconomicos-no-pantanal> Acesso em 15 abr 2021.

HÄBERLE, Peter. Estado Constitucional Cooperativo. Tradução de Marcos Augusto Maliska e Elisete Antoniuk. Rio de Janeiro: Renovar, 2007.

HAJE, Lara; DOEDERLEIN, Natalia. Inpe confirma aumento de quase 200\% em queimadas no Pantanal entre 2019 e 2020. Agência Câmara de Notícias, Brasília, 30 de set. de 2020. Disponível em <https://www.camara.leg.br/noticias/696913-inpe-confirma-aumento-dequase-200-em-queimadas-no-pantanal-entre-2019-e-2020/> Acesso em: 04 mar. de 2021.

IMASUL. Comitê aprova criação de Prêmio para incentivar boas práticas na Reserva da Biosfera do Pantanal. Disponível em <https://www.imasul.ms.gov.br/Geral/reserva-da-biosfera/>. Acesso em 01 mai. 2021.

INPE. Programa Queimadas - Apoio. Disponível em <http:/queimadas.dgi.inpe.br/queimadas/ bdqueimadas/\#> Acesso em 05 mai. 2021.

IRIGARY, Carlos Teodoro José Hugueney; BRAUN, Adriano; IRIGARY, Maira (Orgs.). Pantanal Legal: a tutela jurídica das áreas úmidas e do Pantanal Mato-grossense. Cuiabá: EdUFMT; Carlini \& Caniato Editorial, 2017.

KOTZÉ, Louis J. Global Environmental Constitutionalism in the Anthopocene. [S.1.]: Hart Publishing, 2016.

MEZZAROBA, Orides; MONTEIRO, Cláudia Servilha. Manual de metodologia da pesquisa no direito. 7. ed. São Paulo: Saraiva, 2018.

MMA. Áreas Úmidas - Convenção de Ramsar. Disponível em <https://www.mma.gov.br/ biodiversidade/biodiversidade-aquatica/zonas-umidas-convencao-de-ramsar.html $>$ Acesso em 23 mar 2021.

MMA. Brasil, Bolivia e Paraguai juntos pelo Pantanal. Disponível em <https://www.mma.gov. br/informma/item/14677-noticia-acom-2018-03-2903.html> Acesso em 07 mai 2021.

ONU. Declaração de Estocolmo sobre o Meio Ambiente Humano. Estocolmo, 1972.

RAMSAR CONVENTION SECRETARIAT. An Introduction to the Convention on Wetlands. Gland, Switzerland: Ramsar Convention Secretariat, 2016. 
SECRETARIA DE LA CONVENCIÓN DE RAMSAR. Perspectiva mundial sobre los humedales: Estado de los humedales del mundo y sus servicios a las personas. Suiza, 2018.

SARLET, Ingo Wolfgang; FENSTERSEIFER, Tiago. Direito ambiental: introdução, fundamentos e teoria geral. São Paulo: Saraiva, 2014.

STEFFEN, Will; CRUTZEN, Paul J.; MCNEILL, John. The Anthropocene: are Humans now overwhelming the Great Forces of Nature?. Ambio, v. 36, n. 8, [S.1], 2007.

UN. Sixth Global Environment Outlook. 2019.

VIÑUALES, Jorge E. The Rio Declaration on Environment and Development: a commentary. United Kingdom: Oxford University Press, 2015.

WWF BRASIL. Pantanal. Disponível em <https://www.wwf.org.br/natureza_brasileira/areas_ prioritarias/pantanal/> Acesso em 05 mai. 2021. 